\title{
The Respimat ${ }^{\circledR}$ Development Story: Patient-Centered Innovation
}

Herbert Wachtel · Sabine Kattenbeck · Stephen Dunne •

Bernd Disse

Received: February 10, 2017 / Published online: April 6, 2017

(C) The Author(s) 2017. This article is an open access publication

\section{ABSTRACT}

The Respimat ${ }^{\circledR}$ Soft Mist ${ }^{\mathrm{TM}}$ Inhaler represents a unique delivery system for respiratory medications, using an innovative concept with major technological advancements made during prototype development. The Respimat ${ }^{\circledR}$ concept was driven by the intent to solve problems associated with existing inhaler devices for patient use. The following core aims were achieved: (1) avoiding propellants while reducing requirements for patient coordination and inspiratory effort; (2) optimizing drug delivery to the lungs, and; (3) improving the patients' experience of taking their inhaled medication.

Enhanced content To view enhanced content for this article go to http://www.medengine.com/Redeem/ C708F06011CA2C8B.

H. Wachtel ( $\square)$

Analytical Development, Boehringer Ingelheim, Ingelheim am Rhein, Germany

e-mail: herbert.wachtel@boehringer-ingelheim.com

S. Kattenbeck

Respiratory, Boehringer Ingelheim, Ingelheim

am Rhein, Germany

S. Dunne

Dunne Consultancy Services Ltd., Ipswich, UK

B. Disse

Consultant Respiratory Medicine, Boehringer

Ingelheim, Ingelheim am Rhein, Germany
The Respimat ${ }^{\circledR}$ inhaler is the first-marketed, pocket-sized inhaler to successfully generate a metered dose of therapeutic aerosol mist from an aqueous solution. Patient feedback has strongly influenced the evolution of the Respimat ${ }^{\circledR}$ inhaler design and instructions for use. The availability of Respimat ${ }^{\circledR}$ augments options for clinicians and patients seeking to choose an inhaler that can effectively and consistently deliver respiratory medication to targeted areas of the lung. In many countries worldwide, Respimat ${ }^{\circledR}$ is available for the administration of tiotropium, olodaterol (and tiotropium/olodaterol in fixed-dose combination), ipratropium/fenoterol, and ipratropium/albuterol.

Funding: Boehringer Ingelheim.

Keywords: Aqueous solution; Drug delivery; Drug deposition; Fine particle dose; Inhaled anticholinergic; Inhaled long-acting $\beta_{2}$-agonist; Inspiratory flow; Patient preference; Pocket-sized inhaler; Respimat ${ }^{\circledR}$

\section{INTRODUCTION}

There are currently several different types of inhalers available for the treatment of respiratory diseases. These offer patients and prescribing physicians a choice, but also a challenge, when selecting the best device for an individual [1]. As many inhaled medications for respiratory 
diseases must be taken daily and long term to ensure therapeutic benefit, it is desirable for inhalers to provide efficient, reliable, and well-tolerated drug delivery, and be convenient for patients to use $[1,2]$.

This review article focuses on the rationale for developing and marketing the Respimat ${ }^{\circledR}$ Soft Mist ${ }^{\mathrm{TM}}$ Inhaler as a unique delivery system for several respiratory medications. The Respimat ${ }^{\circledR}$ inhaler available today is the culmination of thorough prototype innovation and development, from the creation and testing of the first component parts to the current inhaler [3-5]. In this article we discuss how patient-centered innovation was at the forefront of the progressive design of Respimat ${ }^{\circledR}$ and consider how technological, esthetic, and other practical enhancements helped to improve drug delivery and patient experience of daily inhaler use.

\section{COMPLIANCE WITH ETHICS GUIDELINES}

This article is based on previously conducted studies and does not involve any new studies of human or animal subjects performed by any of the authors.

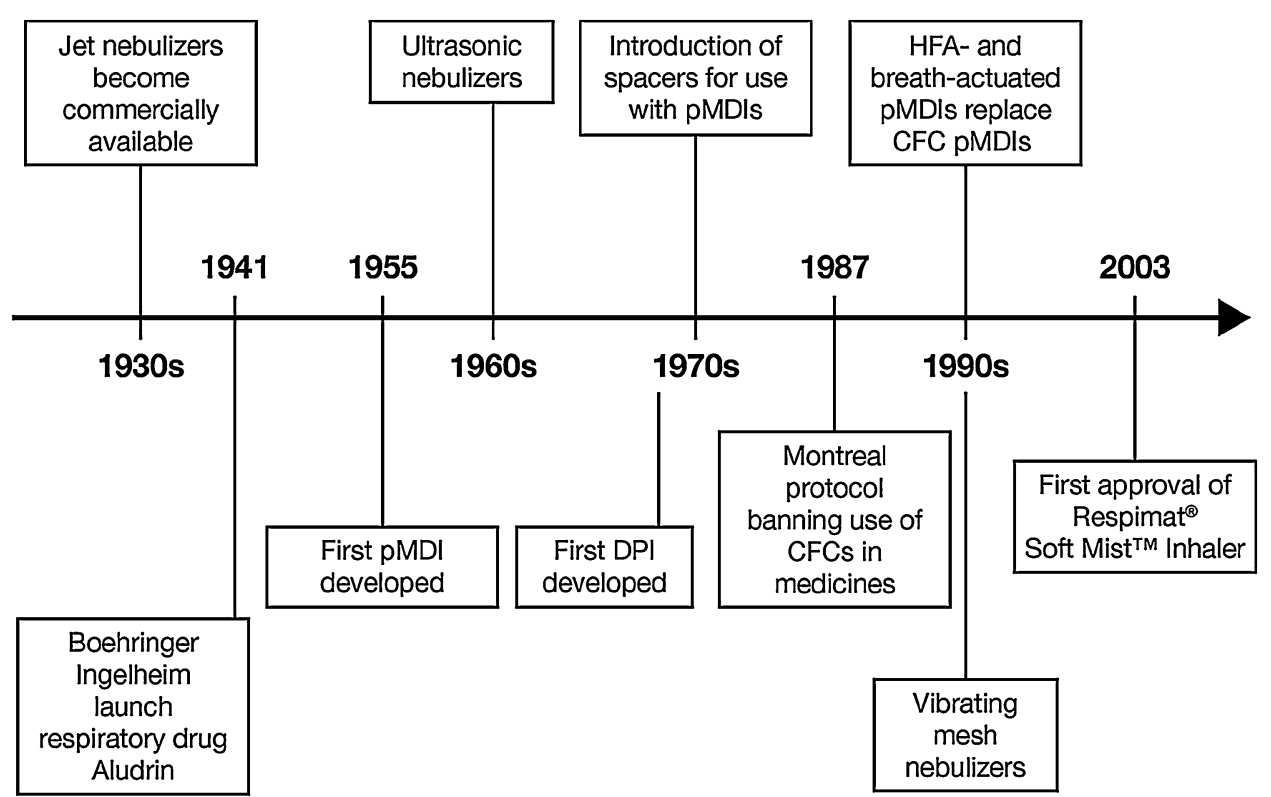

Fig. 1 Historical development of inhaler devices [6-16]. CFC chlorofluorocarbon, DPI dry powder inhaler, HFA hydrofluoroalkane, $p M D I$ pressurized metered dose inhaler

\section{BACKGROUND TO RESPIMAT ${ }^{\circledR}$ DEVELOPMENT}

\section{Factors Affecting the Development and Usability of Alternative Inhalation Devices}

Inhaler devices for respiratory medication have changed significantly since the introduction of the nebulizer in the 1930s and the first pocket-sized, portable devices during the 1950s, 60s, and 70s (Fig. 1) [6-16]. Recognition of the devastating impact of chlorofluorocarbon (CFC) propellants on the ozone layer led to the adoption of the Montreal Protocol by the United Nations in 1987, which imposed a gradual phasing out of the use of ozone-depleting chemicals [17]. Participating countries agreed to eliminate the use of CFCs by January 1997 [14].

As CFCs were used to generate the energy required to produce inhalable drug particles from suspensions in pressurized metered-dose inhalers (pMDI), pharmaceutical companies had to find alternative means of drug delivery $[4,5]$. During the 1990s, hydrofluoroalkane (HFA) MDIs were introduced; HFAs do not affect the ozone layer, although they still contribute to global warming [17]. The HFA pMDIs were 
reformulated to improve drug delivery compared with their CFC counterparts: the introduction of solution aerosols and the use of co-solvents (such as ethanol) resulted in smaller particle sizes and lower plume velocity, thus helping to increase drug deposition in the airways $[3,18]$. However, the short spray duration of HFA pMDIs (less than half a second) and the high velocity of the aerosol (travelling at 2-8 $\mathrm{m} / \mathrm{s}$ ) [19] could result in much of the drug impacting at the back of the throat instead of being inhaled into the lung [3, 4], thereby increasing the risk of local and systemic side effects [1]. Generally, HFA pMDIs still require slow and controlled inhalation for optimal drug deposition [3, 20], and the patient must have adequate coordination to synchronize actuation and inhalation $[4,5]$. To circumvent these coordination problems, spacers and valved holding chambers are used with HFA pMDIs in young children and elderly patients $[1,3]$, and breath-actuated MDIs have been developed as an alternative option [18].

A limited number of dry-powder inhalers (DPI) were introduced before CFCs were phased out and these continue to evolve [5]. Passive DPIs are breath-actuated by design and exclude the need for propellants by using the energy of inspiration to disperse the dry powder and transport inhaled medication to the lungs. However, efficient drug delivery depends on inspiratory effort, lung capacity, and airway narrowing, which vary between patients [3-5]. A certain speed of inhalation is needed to create sufficient turbulent force in the inhaler to disperse the drug into particles small enough to penetrate the airways $[4,21,22]$ and the minimum inspiratory flow rate is device specific: $>90$ $\mathrm{L} / \mathrm{min}$ for a low-resistance DPI, $50-60 \mathrm{~L} / \mathrm{min}$ for a medium-resistance DPI, and $<50 \mathrm{~L} / \mathrm{min}$ for a high-resistance DPI [18]. To further remove the reliance on inspiratory flow rate for adequate inhaler performance, the latest generation of DPIs is active or power assisted [18]. However, the challenge remains to design DPIs that can generate small-particle aerosols reliably and reduce oropharyngeal impaction (which occurs when much of the drug remains bound to its carrier) $[5,22]$. Some DPIs are vulnerable to moisture and require special precautions for use $[5,22]$, which means that they may not be registered for use in hot and humid climate zones.

Nebulizers are portable devices that generate inhalable aerosol particles from an aqueous drug solution or suspension [18]. Rather than using chemical propellants, nebulizers harness alternative sources of energy. Jet (or pneumatic) nebulizers utilize the impact between high-velocity gas and liquid, whereas ultrasonic nebulizers use a high-oscillation frequency $(>1$ MHZ). Vibrating mesh nebulizers, introduced more recently, have shown improved efficiency and reliability of drug delivery, and are quieter and more portable than jet nebulizers $[18,23]$. As nebulizers omit the need for patient coordination between inhalation and actuation, they are particularly useful for delivering respiratory drugs in non-ambulatory or elderly patients with asthma or chronic obstructive pulmonary disease (COPD), or in children with lung conditions [1, 3, 23, 24]. However, many nebulizers are bulky and differ in their efficiency; much of the drug dose is lost during exhalation [1]. As it is not always mandatory for a specific drug solution to be partnered with a particular nebulizer, there may be a risk of inconsistent dosing. Nebulizers also require regular cleaning and maintenance to preserve operational efficiency and to avoid bacterial burden (contamination) $[1,3]$.

\section{Rationale for Respimat ${ }^{\circledR}$ Development}

The concept and development of the Respimat ${ }^{\circledR}$ Soft Mist ${ }^{\mathrm{TM}}$ Inhaler were driven by the intent to solve the problems associated with, and improve the features of, existing inhaler devices. The core aims were to: (1) avoid propellants while reducing requirements for patient coordination and inspiratory effort; (2) optimize drug delivery to the lungs, and; (3) improve the patients' experience of taking their inhaled medication. The rationale behind these goals, and the steps taken to try and achieve them, are described below. 


\section{Avoiding Propellants and the Need for Patient Coordination or Inspiratory Effort}

The spray generation concept for Respimat ${ }^{\circledR}$ was based on positive aspects of nebulizer technology. These included the generation of an aerosol from a liquid (thus avoiding the potential problems of dry powder formulations), avoiding chemical propellants, reducing the requirement for patients to carefully coordinate actuation with inhalation, and lowering the inspiratory effort needed for efficient inhaler operation. The approach taken was unique and different in its attempt to devise a portable, pocket-sized inhaler that could produce an efficient, single-breath inhalable aerosol from a solution. The focus was also on reliability, thus preferring an all-mechanical approach that was powered by compressing a spring [5].

The first innovative prototype inhaler devices specifically designed to reach this goal were developed in the early 1990s, including one using ultrasound nebulization technology, a pressurized, air-powered device (as for conventional nebulizers with a fluid-gas mixing nozzle), and a "high-pressure/small-hole" device; these were able to aerosolize a liquid and generate fine particles of a suitable size for inhalation. The device using ultrasound nebulization was not pursued, as the technology required battery power and performance was considered insufficiently robust. The air-powered device proved impractical for a pocket-sized inhaler but eventually evolved into a capillary atomization system that is used in pocket-sized aerosols today (such as the TRUSPRAY ${ }^{\circledR}$ aerosol system, Lindal Group) [25]. The "high-pressure/ small-hole" device became the Respimat $^{\circledR}$ inhaler.

To reach the objective of producing fine particles from a solution, it was recognized early in Respimat ${ }^{\circledR}$ development that using pressure alone required the use of very small nozzles or holes (typically $5 \mu \mathrm{m}$ in diameter). This was first tested using a laboratory model that had a metal pump, a syringe (solution reservoir), and a lever that compressed a spring to draw solution into the dosing chamber (Fig. 2) [4, 5, 26]. Releasing the spring via a trigger button provided the necessary energy for a piston to force liquid jets at high pressure through microchannels in the nozzle, which generated a "soft mist." This procedure for aerosolizing a liquid resulted in particles of suitable size for inhalation [i.e. a favorable range for the mass-median aerodynamic diameter (fine-particle dose or FPD), $1-5 \mu \mathrm{m}]$, similar to those generated by nebulizer devices [18].

In 1992, the microchannel nozzle from which the aerosol mist was generated on the original laboratory model evolved into the Uniblock, an extremely fine nozzle system incorporating a filter structure, and made of silicon and glass (Fig. 3) [5]. The Uniblock measures just $2.5 \times 2.0 \times 1.1 \mathrm{~mm}^{3}$, and 2000 individual Uniblocks can be made from a single silicon wafer $15 \mathrm{~cm}$ in diameter (using precision technology from the microelectronics industry), thus improving the efficiency of manufacture. The Uniblock nozzle enables selection of the best particle size and spray time for a chosen drug through manipulation of the channel/jet hole size and the impact angle of the spray (as explained below). The component is, therefore, adaptable for delivery of solutions of different physical qualities, containing different respiratory medications.

In parallel to the Uniblock development, the original steel components of the prototype were translated into molded plastics to create a pocket-sized, portable inhaler $[4,5]$. The spring-loading mechanism that provides the energy needed for high-pressure generation of the aerosol was also fine-tuned so that it could be "charged" via a simple half $\left(180^{\circ}\right)$ turn of the inhaler base by the patient $[4,5,27]$. On pressing the dose-release button, the stored mechanical energy from the spring forces the metered drug solution through the Uniblock channels to produce two fine jets of liquid. These converge at a controlled angle to generate the slow-moving, fine mist that is characteristic of the Respimat ${ }^{\circledR}$ inhaler $[4,5]$, and allowed the trademark registration of the "Soft Mist ${ }^{\mathrm{TM}}$ " description [28] (patent numbers: US 5497944 A; US $5662271 \mathrm{~A}$; EP $0521061 \mathrm{~B} 1)$. The energy required to generate the aerosol is mechanical and, as such, the goal of avoiding the use of propellants was achieved. In addition, the 


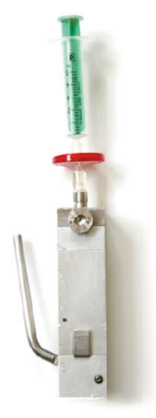

\section{Laboratory model 1991}

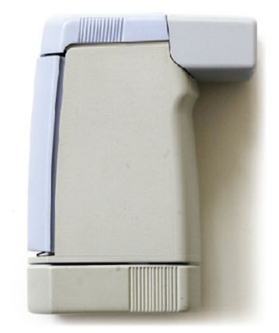

\section{Inverted inhaler} 1992
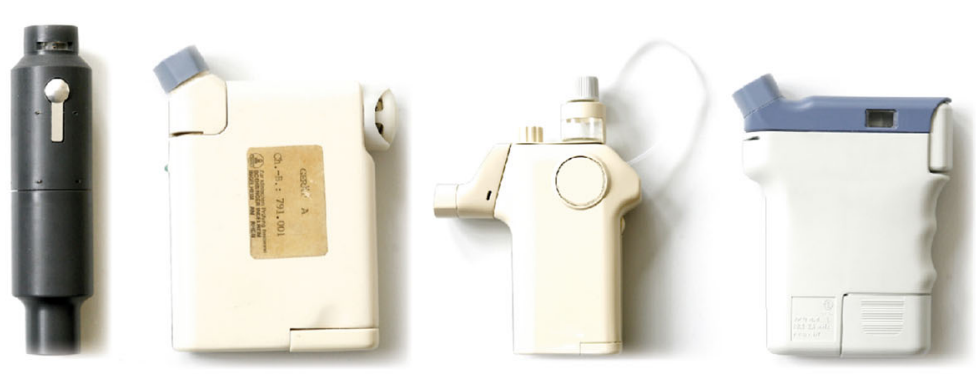

\section{Early inhaler prototypes}

1991
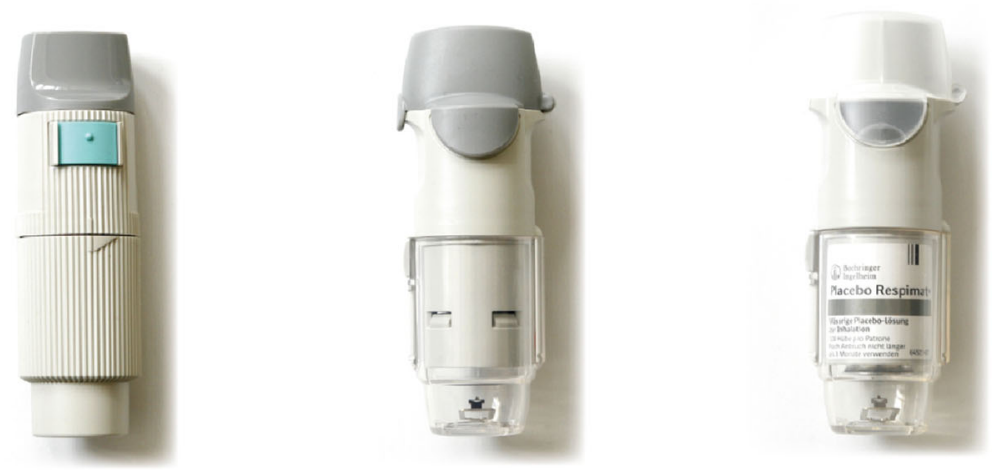

Fig. 2 Evolution of the Respimat ${ }^{\circledR}$ inhaler design
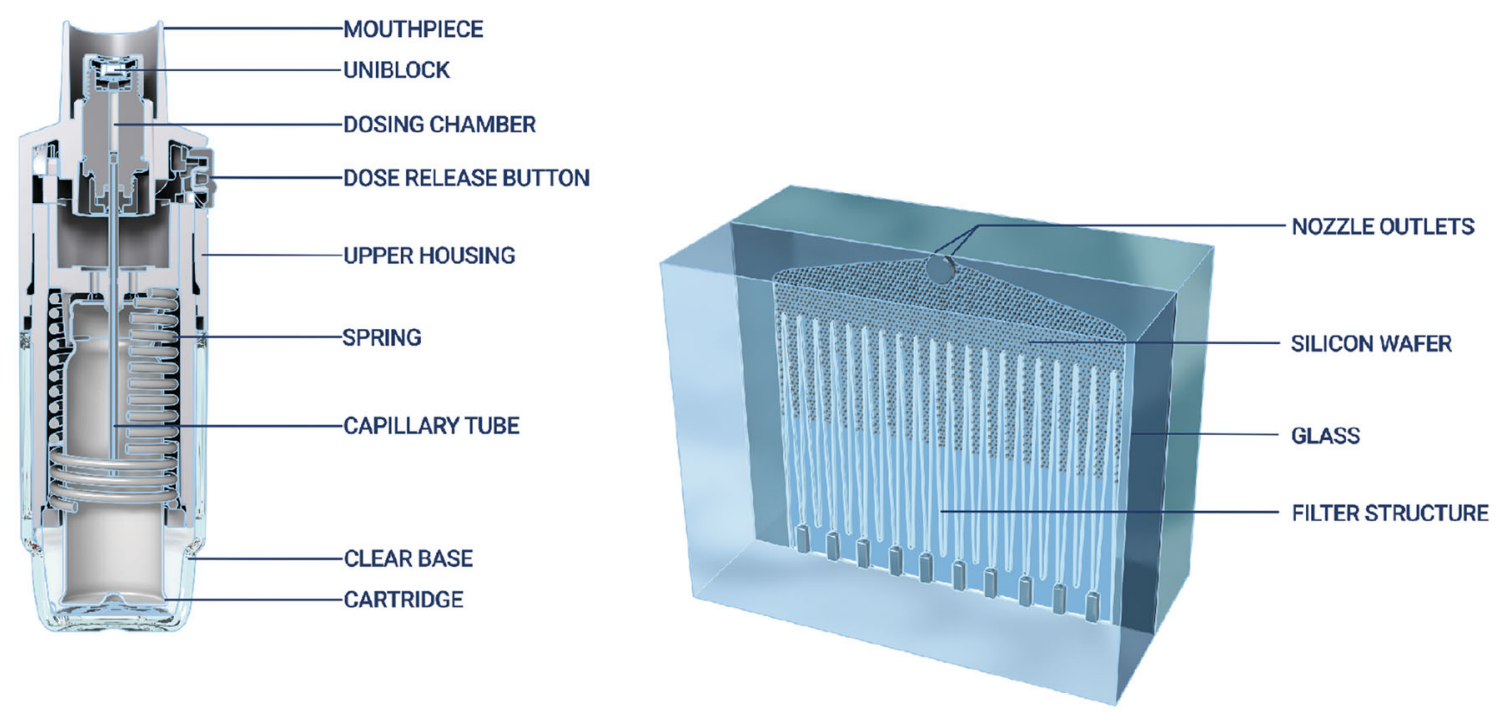

Fig. 3 Schematic diagrams of the Respimat ${ }^{\circledR}$ inhaler and the Uniblock nozzle 
operation of the Respimat ${ }^{\circledR}$ inhaler is not dependent on the patient's inspiratory effort.

The transient pressure involved in generating the spray mist from the Respimat ${ }^{\circledR}$ inhaler is in the region of $25 \mathrm{MN} / \mathrm{m}^{2}$ (250 bar) [5]. However, the velocity of the aerosol emerging from the impact region (which is $\sim 25 \mu \mathrm{m}$ outside the Respimat ${ }^{\circledR}$ Uniblock) is slowed down to $0.8 \mathrm{~m} / \mathrm{s}$, which is $3-10$ times slower than for pMDIs $[5,19]$ and consistent with the lower range of patient inspiratory flow rate [5]. The mean spray duration is $1.2-1.5 \mathrm{~s}$ (versus $0.15-0.36 \mathrm{~s}$ for pMDIs) $[5,19,26]$, which simplifies the coordination of actuation and inhalation for patients (please see the accompanying video available at http://www.medengine.com/ Redeem/C708F06011CA2C8B).

\section{Optimizing Drug Delivery to the Lungs}

The extent to which a respiratory medication effectively relieves symptoms and/or addresses the pathophysiology of lung disease is paramount for inhaler design. The efficiency of drug delivery to the target areas of the lungs must be optimized, and non-pulmonary delivery should be minimal. As a key determinant of the treatment effect, the intended dose of inhaled medication should consistently reach the patient's airways in a comparable distribution with each use of the inhaler.

To obtain regulatory approval, the Respimat ${ }^{\circledR}$ drug delivery system had to meet stringent requirements for the reproducibility of the inhaled dose [5]. The consistency of dosing with the Respimat ${ }^{\circledR}$ inhaler is assisted by the design of the drug cartridge housing, an aluminium cylinder containing a double-walled, plastic, collapsible bag, which contracts as the drug solution is used. This is necessary to ensure that the capillary is always immersed in the solution until the last actuation, independent of the orientation of the inhaler while loading the dose. The size of this cylinder is matched exactly to the internal dimensions of the inhaler. The correct dosage for each actuation is drawn into a fixed-volume dosing chamber from the inner reservoir of the drug cartridge, through a capillary with a non-return valve (Fig. 3) $[4,5]$. This process ensures uniformity of spray volume, with no tail-off effect as the cartridge is depleted [3].

The Respimat ${ }^{\circledR}$ inhaler improves drug penetration into the airways by optimizing three other device characteristics: aerosol velocity, particle size, and internal resistance [5, 29]. For an inhaled medication to be effective for respiratory diseases, the drug must reach the peripheral airways. If the aerosol velocity is too fast, the risk of inertial impaction on the throat is increased, whereas a low-velocity aerosol is more likely to result in drug sedimentation in the peripheral lung and have the intended therapeutic action $[3,29]$. Particles that are too large $(\geq 6 \mu \mathrm{m})$ will deposit in the oropharynx [3] and large conducting airways, having minimal-to-no clinical impact, whereas particles that are too small $(<1 \mu \mathrm{m})$ may not deposit at all and are exhaled. Inhalers generating a high FPD are able to deposit more drug particles in clinically meaningful areas (i.e. the medium-to-small airways and peripheral bronchioles). The FPD of an aerosol cloud is the proportion of drug mass included in aerosolized particles with an aerodynamic diameter $\leq 5.0 \mu \mathrm{m}[5,30]$. More than $60 \%$ of the drug dose expelled by Respimat ${ }^{\circledR}$ falls within an FPD of $\leq 5.0 \mu \mathrm{m}$ [31], which accentuates sedimentation of particles in the smaller bronchi and bronchioles [32]. Extensive overall drug deposition in the lungs with Respimat ${ }^{\circledR}$ use has been shown by gamma scintigraphy studies [3, 33-35].

Taken together, the performance characteristics of the Respimat ${ }^{\circledR}$ inhaler ensure the enhanced delivery of inhaled medication to the patient. The improved efficiency in the delivery of inhaled medication to the lung with Respimat $^{\circledR}$ has also allowed reduction of the nominal drug dose without loss of pharmacodynamic effect or clinical efficacy in asthma and COPD [5, 36-39]. For example, clinical studies in COPD have shown the comparable bronchodilator efficacy and systemic exposure of once-daily tiotropium Respimat ${ }^{\circledR} 5 \mu \mathrm{g}$ and tiotropium HandiHaler ${ }^{\circledR} 18 \mu \mathrm{g}[38,40]$. 


\section{Improving Patient Experience of Inhaler Use}

\section{Patient-Centered Design Innovation}

To improve patient experience of inhaler use, esthetic and practical advances in Respimat ${ }^{\circledR}$ design were made on the basis of feedback from patient and health care provider usability studies, where alternative pocket-sized, molded-plastic prototypes were tested (Fig. 2) $[3,4]$. The earliest prototypes had limitations: for example, the 1992 version was inverted (operated with the mouthpiece at the top), which could be confusing for patients, because it was so different from commonly used pMDIs. The first design used in clinical trials (1994) was cylindrical and had a detachable cap, but this could be lost. However, the enhanced and subsequently marketed version of the Respimat ${ }^{\circledR}$ inhaler [unchanged since the 2003 approval of Respimat ${ }^{\circledR}$ Berodual $^{\circledR}$ (ipratropium bromide and fenoterol hydrobromide)] has incorporated features to improve visual appeal and usability, based on user feedback. The current inhaler has color coding (to identify the drug class), a transparent base (to identify the drug product and the cartridge insertion), a cap covering the dose-release button (to avoid accidental release when turning the base) that is hinged (to avoid misplacement), a locking mechanism (activated when the labelled actuations are dispensed), and a dose indicator, which enters a red zone when only 7 days' medication remains $[4,26,41,42]$. As the development of Respimat ${ }^{\circledR}$ was complete before first marketing, the overall inhaler platform has remained constant for more than a decade [41], eliminating the need for patients to adapt to design changes.

The latest development process for the Respimat ${ }^{\circledR}$ inhaler was to assess its suitability for use with a valved holding chamber (spacer) and facemask for young pediatric patients. A study assessing handling and inhalation flow profiles found that all children aged $<5$ years could achieve inhalation success with basic training and assistance from a parent/caregiver [43]. The assessment of the theoretical dose delivered to the lung from inhalation flow profiles has been shown to confirm and complement pharmacokinetic analyses conducted in clinical trials of children of the same age group with cystic fibrosis [44].

\section{Respimat $^{\circledR}$ Handling and Usability}

Inhalers must be operated correctly to ensure that the desired therapeutic effect is achieved, and this is strongly influenced by intuitive use. In addition, successful drug delivery to the lungs (as determined by a physician) is associated with patient satisfaction with their inhaler device; satisfaction promotes long-term compliance with respiratory maintenance therapy and is linked to improved clinical outcomes [1, 3, 45-47]. Assessments conducted during clinical trials and studies using self-report instruments [including simple surveys specific to Respimat ${ }^{\circledR}$, the validated Patient Satisfaction and Preference Questionnaire (PASAPQ) and the Handling Questionnaire (an investigational tool)] have suggested that patients with COPD or asthma find Respimat $^{\circledR}$ easy to operate $[3,45,48-53]$ and prefer this inhaler over other types of device, such as pMDIs or DPIs [3, 49-52, 54].

Clinical trials and handling studies have also shown that Respimat ${ }^{\circledR}$ can be used over the complete age range, from toddlers to seniors. It provides efficient drug delivery in pediatric patients [37, 43, 55], including children $<5$ years when using a spacer $[27,43]$. In one study, anecdotal evidence suggested that children aged 6-15 years found it easy to learn how to use Respimat ${ }^{\circledR}$ and preferred this inhaler to using an MDI [37]. In a study of children aged 4-12 years, there was a high rate of successful inhalation maneuvers (75\%), comparing favorably to reported success rates from usability studies of DPIs [55].

Correct inhaler use is a prerequisite for adequate patient adherence [47], and Respimat ${ }^{\circledR}$ was designed for easy daily use. To prepare for first use of Respimat ${ }^{\circledR}$, the patient inserts the drug cartridge and primes it by turning the base until it clicks, opening the cap, and pressing the dose-release button. This process is repeated until a visible spray is seen upon pressing of the dose-release button $[4,5,27,42]$. Then, these steps are repeated three more times. Once primed, Respimat ${ }^{\circledR}$ operates as a "pressand-breathe" inhaler, and patients follow 


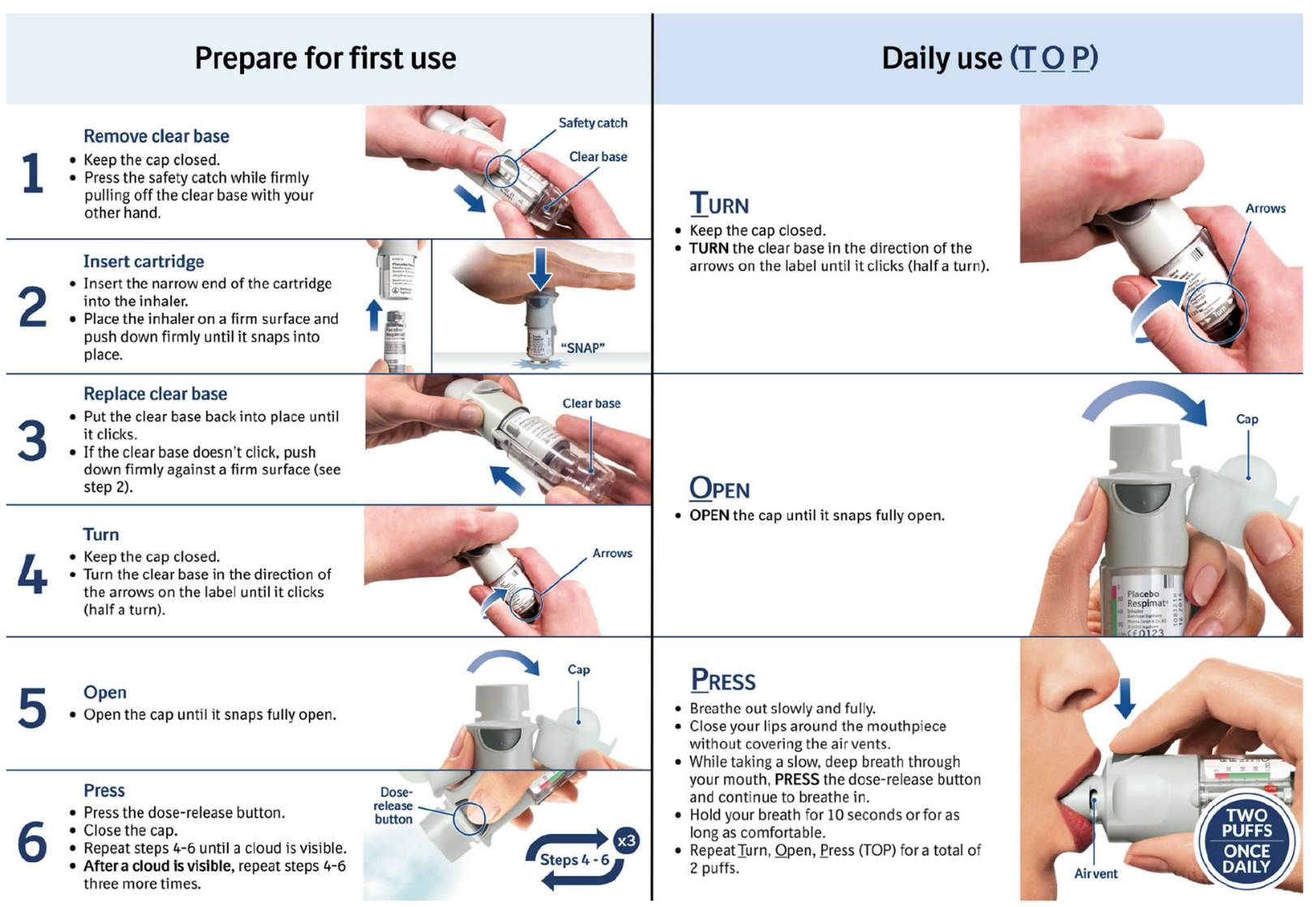

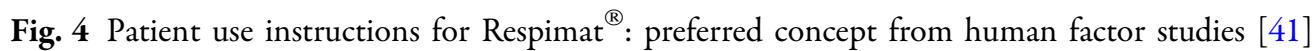

three-step instructions for use-TURN, OPEN, PRESS [27]. To ensure that Respimat ${ }^{\circledR}$ handling instructions are simple to follow (with minimal chance of error), human-factor studies were recently conducted in the European Union, the United States of America, South America, and Japan [41] in accordance with US Food and Drug Administration guidelines for medical devices [56]. Three alternative sets of instructions were tested for use errors, as well as patients' understandability and preference. As a result of the feedback obtained, the Respimat ${ }^{\circledR}$ instructions have been modified with improved layout, color-coded "Prepare" and "Daily use" sections, an improved focus on essential handling steps, use of concise bulleted text, and the incorporation of larger images (Fig. 4) [41].

Table 1 Proposed features of the 'ideal' inhaler (adapted from [22]) that apply to Respimat ${ }^{\circledR}$

\begin{tabular}{lll}
\hline Drug delivery & Patient use & Pharmaceutical concerns \\
\hline High lung deposition $[33,34]$ & Simple to use [45] & Absence of propellants \\
Aerosol generation independent of inspiration [5] & Portable and pocket-sized [58] & Uniformity of dose \\
Prolonged actuation time ( $>1 \mathrm{~s})[19]$ & Multi-dose ( $>50$ actuations) [42] & Resistant to contamination \\
High FPD of aerosol [4] & Dose counter [42] & No vulnerability to humidity [5]
\end{tabular}

Slow-velocity aerosol [19]

FPD fine particle dose 


\section{Other Practical Use Considerations}

The Respimat ${ }^{\circledR}$ inhaler products have a long shelf life (3 years) and a 3-month in-use time following the first actuation [57]. To cover 1-month use, Respimat ${ }^{\circledR}$ can be tailored to dispense up to 120 actuations from a single drug cartridge, depending on the frequency of dosing of the prescribed drug regimen [5]. The design of the Respimat ${ }^{\circledR}$ inhaler and drug cartridge means that it is not susceptible to contamination [5], and the drug solution is formulated with water and added preservatives to ensure microbial stability $[4,5]$. As the aerosol is generated from a solution rather than a dry powder, there is no vulnerability to moisture, which supports use in humid climate zones.

Overall, the Respimat $^{\circledR}$ inhaler displays many of the proposed features of an "ideal" inhaler device [22] with regard to the mechanics of drug delivery, the patient's experience of using their inhaler, and other general pharmaceutical aspects (Table 1) [58].

\section{CONCLUSIONS}

The introduction of Respimat $^{\circledR}$ represents a major technological advance in inhaler design for the delivery of respiratory medication. It is the first marketed, pocket-sized inhaler to successfully generate a metered dose of therapeutic aerosol mist from an aqueous solution for the treatment of lung diseases. Patient feedback strongly influenced the evolution of the Respimat ${ }^{\circledR}$ inhaler design and instructions for use, and patients have reported ease of handling and preference for this inhaler over alternative devices. The availability of Respimat ${ }^{\circledR}$ (currently approved for the delivery of the long-acting anticholinergic tiotropium, the long-acting $\beta_{2}$-agonist olodaterol, and fixed-dose combinations of these classes: olodaterol/tiotropium, ipratropium/albuterol, and ipratropium/fenoterol) augments options for clinicians and patients seeking to choose an inhaler that can effectively and consistently deliver respiratory medication to targeted areas of the lung. Boehringer Ingelheim is continuing in its efforts to further improve the usability and versatility of the Respimat ${ }^{\circledR}$ inhaler, in parallel with developing new substances for administration via Respimat ${ }^{\circledR}$ in the indication areas of cystic fibrosis and COPD.

\section{ACKNOWLEDGEMENTS}

All named authors meet the International Committee of Medical Journal Editors (ICMJE) criteria for authorship for this manuscript, take responsibility for the integrity of the work as a whole, and have given final approval for the version to be published. Scientific writing and editorial support was provided by Helen Beaumont D.Phil. at PAREXEL, funded by Boehringer Ingelheim. Article processing charges for this publication were funded by Boehringer Ingelheim.

Disclosures. Herbert Wachtel is an employee of Boehringer Ingelheim and has a patent (WO2004024340A1-Blockiervorrichtung für ein Sperrspannwerk) with royalties paid according to German law regulating inventions by employees. Sabine Kattenbeck is an employee of Boehringer Ingelheim. Stephen Dunne has nothing to disclose. Bernd Disse was an employee of Boehringer Ingelheim until July 2015.

Compliance with Ethics Guidelines. This article is based on previously conducted studies and does not involve any new studies of human or animal subjects performed by any of the authors.

Data Availability. Data sharing is not applicable to this article as no datasets were generated or analyzed.

Open Access. This article is distributed under the terms of the Creative Commons Attribution-NonCommercial 4.0 International License (http://creativecommons.org/licenses/ by-nc/4.0/), which permits any noncommercial use, distribution, and reproduction in any medium, provided you give appropriate credit to the original author(s) and the source, provide a link to the Creative Commons license, and indicate if changes were made. 


\section{REFERENCES}

1. Ari A, Fink JB. Guidelines for aerosol devices in infants, children and adults: which to choose, why and how to achieve effective aerosol therapy. Expert Rev Respir Med. 2011;5(4):561-72.

2. Islam N, Cleary MJ. Developing an efficient and reliable dry powder inhaler for pulmonary drug delivery-a review for multidisciplinary researchers. Med Eng Phys. 2012;34(4):409-27.

3. Anderson P. Use of Respimat Soft Mist inhaler in COPD patients. Int J Chron Obstruct Pulmon Dis. 2006;1(3):251-9.

4. Dalby R, Spallek M, Voshaar T. A review of the development of Respimat Soft Mist Inhaler. Int J Pharm. 2004;283(1-2):1-9.

5. Dalby RN, Eicher J, Zierenberg B. Development of Respimat ${ }^{\circledR}$ Soft Mist Inhaler and its clinical utility in respiratory disorders. Med Devices (Auckl). 2011;4:145-55.

6. Dolovich MB, Ahrens RC, Hess DR, et al. Device selection and outcomes of aerosol therapy: evidence-based guidelines: American College of Chest Physicians/American College of Asthma, Allergy, and Immunology. Chest. 2005;127(1):335-71.

7. Boehringer Ingelheim Limited. 1885-1948: innovative beginnings. Boehringer Ingelheim web site. https://www.boehringer-ingelheim.com/history/ history-milestone/1885-1948. Accessed 20 July 2016 A.D.

8. Freedman T. Medihaler therapy for bronchial asthma; a new type of aerosol therapy. Postgrad Med. 1956;20(6):667-73.

9. Mercer TT. Production of therapeutic aerosols; principles and techniques. Chest. 1981;80(6 Suppl):813-8.

10. Muers MF. Overview of nebuliser treatment. Thorax. 1997;52(Suppl 2):S25-30.

11. Bell JH, Hartley PS, Cox JS. Dry powder aerosols. I. A new powder inhalation device. J Pharm Sci. 1971;60(10):1559-64.

12. Morén F. Drug deposition of pressurised inhalation aerosols. I. Influence of actuator tube design. Int J Pharm. 1978;1:205-12.

13. Newman SP, Moren F, Pavia D, Little F, Clarke SW. Deposition of pressurized suspension aerosols inhaled through extension devices. Am Rev Respir Dis. 1981;124(3):317-20.
14. Leach CL. Approaches and challenges to use freon propellant replacements. Aerosol Sci Technol. 1995;22(4):328-34.

15. O'Callaghan C, Barry PW. The science of nebulised drug delivery. Thorax. 1997;52(Suppl 2):S31-44.

16. Berodual Respimat (summary of product characteristics) (2004). Boehringer Ingelheim Limited; 2004.

17. European Commission (2016). The Montreal Protocol. European Commission. www.ec.europa.eu/ clima/publications/docs/montreal_prot_en.pdf. Accessed 22 April 2016.

18. Lavorini F, Fontana GA, Usmani OS. New inhaler devices-the good, the bad and the ugly. Respiration. 2014;88(1):3-15.

19. Hochrainer D, Holz H, Kreher C, Scaffidi L, Spallek $\mathrm{M}$, Wachtel $\mathrm{H}$. Comparison of the aerosol velocity and spray duration of Respimat Soft Mist inhaler and pressurized metered dose inhalers. J Aerosol Med. 2005;18(3):273-82.

20. Newman SP, Weisz AW, Talaee N, Clarke SW. Improvement of drug delivery with a breath actuated pressurised aerosol for patients with poor inhaler technique. Thorax. 1991;46(10):712-6.

21. Fink JB, Rubin BK. Problems with inhaler use: a call for improved clinician and patient education. Respir Care. 2005;50(10):1360-74.

22. Ganderton D. Targeted delivery of inhaled drugs: current challenges and future goals. J Aerosol Med. 1999;12(Suppl 1):S3-8.

23. Ibrahim M, Verma R, Garcia-Contreras L. Inhalation drug delivery devices: technology update. Med Devices (Auckl). 2015;8:131-9.

24. Heijerman H, Westerman E, Conway S, Touw D, Doring G. Inhaled medication and inhalation devices for lung disease in patients with cystic fibrosis: a European consensus. J Cyst Fibros. 2009;8(5):295-315.

25. Lindal Group (2016). Dispensing Systems TRUSPRAY ${ }^{\circledR}$. lindalgroup.com. http://www.lindalgroup. com/uploads/media/Truspray_EN.pdf. Accessed 19 May 2016.

26. Zierenberg B. Optimizing the in vitro performance of Respimat. J Aerosol Med. 1999;12(Suppl 1):S19-24.

27. Spiriva (tiotropium) Respimat 2.5 micrograms, solution for inhalation (summary of product characteristics) (2016). Boehringer Ingelheim Limited; 2016. 
28. Boehringer Ingelheim Limited (2016). Respimat ${ }^{\circledR}$. Respimat.com. http://experts.respimat.com/home1. html. Accessed 9 June 2016.

29. Capstick TG, Clifton IJ. Inhaler technique and training in people with chronic obstructive pulmonary disease and asthma. Expert Rev Respir Med. 2012;6(1):91-101.

30. Nichols SC, Mitchell JP, Sandell D, et al. A Multi-laboratory in vitro study to compare data from abbreviated and pharmacopeial impactor measurements for orally inhaled products: a report of the European Aerosol Group (EPAG). AAPS PharmSciTech. 2016;17(6):1383-92.

31. Wachtel H, Moser A. The Respimat ${ }^{\circledR}$, a new Soft Mist ${ }^{\mathrm{TM}}$ inhaler for Delivering Drugs to the Lungs. In: Rathbone MJ, Hadgraft J, Roberts MS, Lane ME, editors. Modified release drug delivery technology. 2nd ed. London: Taylor \& Francis; 2008. p. 637-45.

32. Lippmann M. Deposition and clearance of inhaled particles in the human nose. Ann Otol Rhinol Laryngol. 1970;79(3):519-28.

33. Newman SP, Brown J, Steed KP, Reader SJ, Kladders $\mathrm{H}$. Lung deposition of fenoterol and flunisolide delivered using a novel device for inhaled medicines: comparison of RESPIMAT with conventional metered-dose inhalers with and without spacer devices. Chest. 1998;113(4):957-63.

34. Pitcairn G, Reader S, Pavia D, Newman S. Deposition of corticosteroid aerosol in the human lung by Respimat Soft Mist inhaler compared to deposition by metered dose inhaler or by Turbuhaler dry powder inhaler. J Aerosol Med. 2005;18(3):264-72.

35. Brand P, Hederer B, Austen G, Dewberry H, Meyer T. Higher lung deposition with Respimat Soft Mist inhaler than HFA-MDI in COPD patients with poor technique. Int $\mathrm{J}$ Chron Obstruct Pulmon Dis. 2008;3(4):763-70.

36. Kilfeather SA, Ponitz HH, Beck E, et al. Improved delivery of ipratropium bromide/fenoterol from Respimat Soft Mist Inhaler in patients with COPD. Respir Med. 2004;98(5):387-97.

37. von Berg A, Jeena PM, Soemantri PA, et al. Efficacy and safety of ipratropium bromide plus fenoterol inhaled via Respimat Soft Mist Inhaler vs. a conventional metered dose inhaler plus spacer in children with asthma. Pediatr Pulmonol. 2004;37(3):264-72.

38. Hohlfeld JM, Sharma A, van Noord JA, et al. Pharmacokinetics and pharmacodynamics of tiotropium solution and tiotropium powder in chronic obstructive pulmonary disease. J Clin Pharmacol. 2014;54(4):405-14.
39. Wise RA, Anzueto A, Cotton D, et al. Tiotropium Respimat inhaler and the risk of death in COPD. N Engl J Med. 2013;369(16):1491-501.

40. Calverley PM, Konen-Bergmann M, Richard F, Bell S, Hohlfeld JM. Tiotropium Respimat versus HandiHaler: comparison of bronchodilator efficacy of various doses in clinical trials. Adv Ther. 2016;33(5):786-93.

41. Kattenbeck S (2016) Human factor studies. Case study instructions for use for Respimat ${ }^{\circledR}$. Presented at: IPAC-RS symposium 2016 at RDD 2016: Meeting the quality challenge for orally inhaled drug products, Scottsdale, Arizona, 21 April 2016.

42. SPIRIVA Respimat Using your SPIRIVA Respimat inhaler (2015). Boehringer Ingelheim Ltd.

43. Kamin W, Frank M, Kattenbeck S, Moroni-Zentgraf $\mathrm{P}$, Wachtel $\mathrm{H}$, Zielen $\mathrm{S}$. A handling study to assess use of the Respimat ${ }^{\circledR}$ Soft Mist ${ }^{\mathrm{TM}}$ inhaler in children under 5 years old. J Aerosol Med Pulm Drug Deliv. 2015;28(5):372-81.

44. Bickmann D, Kamin W, Sharma A, Wachtel H, Moroni-Zentgraf $\mathrm{P}$, Zielen S. In vitro determination of Respimat dose delivery in children: an evaluation based on inhalation flow profiles and mouth-throat models. J Aerosol Med Pulm Drug Deliv. 2015;29(1):76-85.

45. Hodder R, Price D. Patient preferences for inhaler devices in chronic obstructive pulmonary disease: experience with Respimat Soft Mist inhaler. Int J Chron Obstruct Pulmon Dis. 2009;4:381-90.

46. Braido F, Chrystyn H, Baiardini I, et al. "Trying, But Failing" - the role of inhaler technique and mode of delivery in respiratory medication adherence. J Allergy Clin Immunol Pract. 2016;4(5):823-32.

47. Rogueda P, Traini D. The future of inhalers: how can we improve drug delivery in asthma and COPD? Expert Rev Respir Med. 2016;10(10):1041-4.

48. Asakura Y, Nishimura N, Maezawa K, Terajima T, Kizu J, Chohnabayashi N. Effect of switching tiotropium HandiHaler ${ }^{\circledR}$ to Respimat $^{\circledR}$ Soft Mist Inhaler in patients with COPD: the difference of adverse events and usability between inhaler devices. J Aerosol Med Pulm Drug Deliv. 2013;26(1):41-5.

49. Hodder R, Reese PR, Slaton T. Asthma patients prefer Respimat Soft Mist Inhaler to Turbuhaler. Int J Chron Obstruct Pulmon Dis. 2009;4:225-32.

50. Dal Negro RW, Povero M. Acceptability and preference of three inhalation devices assessed by the Handling Questionnaire in asthma and COPD patients. Multidiscip Respir Med. 2015;11:7. 
51. Miravitlles M, Montero-Caballero J, Richard F, et al. A cross-sectional study to assess inhalation device handling and patient satisfaction in COPD. Int J Chron Obstruct Pulmon Dis. 2016;11:407-15.

52. Schurmann W, Schmidtmann S, Moroni P, Massey D, Qidan M. Respimat Soft Mist inhaler versus hydrofluoroalkane metered dose inhaler: patient preference and satisfaction. Treat Respir Med. 2005;4(1):53-61.

53. Dal Negro RW, Povero M. The economic impact of educational training assessed by the Handling Questionnaire with three inhalation devices in asthma and Chronic Obstructive Pulmonary Disease patients. Clinicoecon Outcomes Res. 2016;8:171-6.

54. Dekhuijzen PN, Lavorini F, Usmani OS. Patients' perspectives and preferences in the choice of inhalers: the case for Respimat $\left({ }^{\circledR}\right)$ or HandiHaler $\left({ }^{\circledR}\right)$. Patient Prefer Adherence. 2016;10:1561-72.
55. Kamin W, Krackhardt D, Goessl R, et al. A handling study to assess the use of the Respimat ${ }^{\circledR}$ Soft Mist ${ }^{\mathrm{TM}}$ Inhaler in children aged 4-12 years. Pulm Ther. 2015;1:53-63.

56. US Food and Drug Administration (2016). Human factors studies and related clinical study considerations in combination product design and development. Draft guidance for industry and FDA staff. US FDA website. http://www.fda.gov/downloads/ regulatoryinformation/guidances/ucm484345.pdf. Accessed 25 May 2016.

57. SPIRIVA $^{\circledR} \quad$ RESPIMAT $^{\circledR} \quad$ (tiotropium bromide) inhalation spray foi Ridgefield, CT, USA: Boehringer Ingelheim Pharmaceuticals, Inc.; 2016.

58. Moroni-Zentgraf P. Impact of patient needs on design and usage of an inhalation device in respiratory medicine. Respir Drug Deliv Eur. 2013;1:141-52. 